\title{
Ortho-Methoxy Group as a Mild Inhibitor of the Reactions Between Carboxylic Acid and Phenols
}

\author{
Andrea Guljas, ${ }^{1,2}$ Anita Rágyanszki, ${ }^{1,2, *}$ Béla Fiser, ${ }^{2}$ Béla Viskolcz, ${ }^{2}$ Imre G. Csizmadia ${ }^{1,2}$
}

1 Department of Chemistry, University of Toronto, Toronto, ON, Canada, M5S 3H6
2 Institute of Chemistry, Faculty of Material Science, University of Miskolc, Miskolc, HU 3515
${ }^{*}$ Corresponding author's e-mail address: a.ragyanszki@utoronto.ca

RECEIVED: June 14, 2017 REVISED: August 23, 2017 \ ACCEPTED: September 19, 2017

Abstract: According to the current database of natural products, over 25,000 compounds contain a vanillyl ring in their structure. The reasoning behind the high occurrence of the vanillyl ring structure seemed to be poorly understood, specifically the preference for a methoxy-substituted phenol structure as opposed to its dihydroxy analogue. To better understand this, we investigated the reaction mechanisms of two methoxyphenol structures, in syn and anti conformations, two hydroxyphenol structures, also in syn and anti conformations, and phenol as a reference structure, with acetic acid. Of the starting structures, the syn hydroxyphenol was found to be kinetically the most reactive, and formed the most stable product, while both hydroxyl-substituted phenols reacted more favorably with acetic acid than the methoxyphenols. A preference for the methoxyphenol molecule may exist as a way to hinder the formation of stable covalent bonds between natural products and cellular components.

Keywords: vanillyl ring, capsaicin, gingerol, quantum chemical calculations, esterification.

\section{INTRODUCTION}

$\mathbf{T}$ HE aromatic moiety of vanillyl acid consists of an ortho-methoxy phenol structure, which is a frequently occurring structure in natural products. The current database of natural products contains over 25,000 compounds containing this structure. ${ }^{[1]}$ Perhaps the most well-known compound containing the vanillyl ring moiety is vanillin (Figure 1a). Vanillin is the major component of vanilla, a widely used compound used for flavoring. ${ }^{[2]}$ In addition, approximately half of the synthetically produced vanillin worldwide is used in industries for the production of food preservatives, herbicides, and pharmaceutical. ${ }^{[3,4]}$ These applications are possible as a result of the antioxidant and antimicrobial properties of vanillin. ${ }^{[4]}$ When administered in high concentrations, the antioxidant effect of vanillin also is sufficient to prevent oxidative damage in mammalian cells. ${ }^{[5]}$

The vanillyl acid moiety is also present in ligands of the vanilloid receptor, or transient receptor potential cation channel, subfamily $\mathrm{V}$, member 1 (TRPV1), namely in capsaicin, gingerol, and shogaol. Capsaicin (Figure 1b) is the most prevalent member of the capsaicinoid family, and is the active component in chilli peppers, responsible for their characteristic spiciness. ${ }^{[6,7]}$ In addition to their various physiological and biological capabilities, such as acting as anti-nociceptive and anti-inflammatory analgesics, ${ }^{[8]}$ capsaicinoids have been shown to be potent antioxidants. ${ }^{[9,10]}$ Capsaicin specifically is able to scavenge various radicals at numerous locations within cells, ${ }^{, 11]}$ contributing to its anticarcinogenic activities. These properties have been demonstrated in a number of cancerous cells, including human gastric cancer cells, ${ }^{[12]}$ leukemic cells, ${ }^{[13]}$ and prostate cancer cells. ${ }^{[14,15]}$ Gingerol (Figure 1c) and shogaol (Figure 1d), as is the case with capsaicinoids, have a significant affinity for the TRPV receptors. ${ }^{[16]}$ Both molecules are active constituents of ginger, a popular culinary spice and a widely used product in traditional oriental herbal medicine for the treatment of various diseases including headache, infections, and muscle ache, among others. ${ }^{[17,18]}$ The properties of these compounds have been shown to include antioxidant, anticancer, antimicrobial, and anti-inflammatory properties. ${ }^{[19,20]}$ 


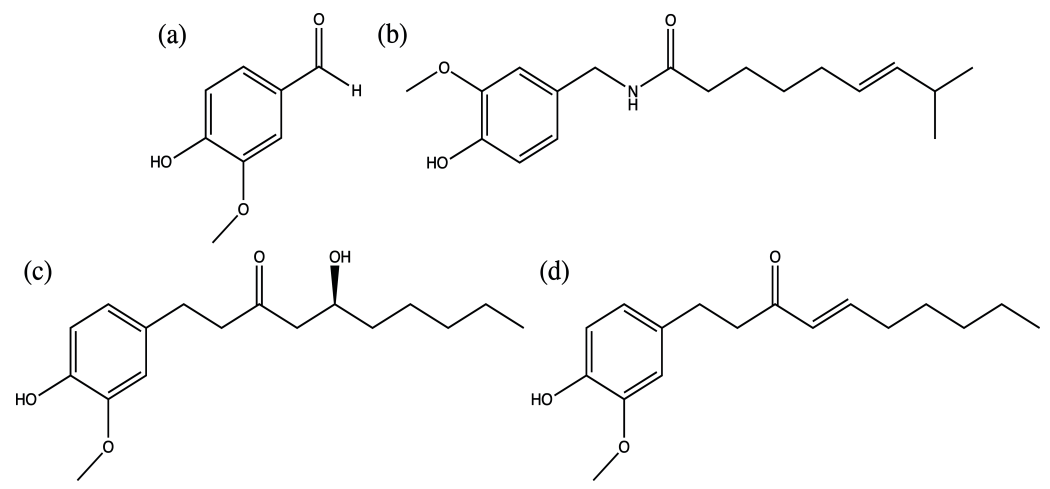

Figure 1. Chemical structures of (a) vanillin, (b) capsaicin, (c) gingerol, and (d) shogaol.

It seemed reasonable to assume that nature had a purpose in placing so many ortho-methoxy groups in natural products. Other studies have shown that methyl groups are found in chemical reactions in nature; for instance, a recent study has shown that the methylation of histamine transforms a non-substrate, histamine, into an excellent substrate, $\mathrm{N}$-methylhistamine, for the monoamino oxidase enzyme, increasing the reactivity of the methylated system and promoting its binding to the active site. ${ }^{[21]}$ It occurred that perhaps the ortho-methoxy group, due to its steric closeness to the hydroxyl group, is perhaps involved in intramolecular van der Waals interactions that would finetune the acidity of the vanillyl ring. Compounds containing a phenol group are known to act as antioxidants, potentially due to the relatively weak bond dissociation enthalpy of the phenolic hydrogen. ${ }^{[22]}$ In both the synthetic and the biological synthesis of some compounds containing the vanillyl ring moiety, a hydroxyphenol group is formed before the methylation of one of the hydroxyl groups in order to produce a methoxyphenol. ${ }^{[23-27]}$ In the synthesis pathways of both vanillin and capsaicin, for instance, 3,2dihydroxycinnamic acid is first formed and subsequently methylated by caffeic acid o-methyltransferase to 3-hydroxy-4-methoxycinnamic acid.[23-27] These pathways seem to support a preference for the methylated phenol over the hydroxyl phenol structure. In order to study the reductive potential of 2-methoxy-substituted phenols relative to 2-hydroxy-substituted phenols, we conducted a computational analysis of the interaction of both hydroxyphenol and methoxyphenol structures with a carboxylic acid functional group, meant to serve as a possible cellular molecule such as a glutamic acid residue. We compared the free energies, bond lengths, and transition state structures of the complex formation reactions between the various orientations of the structures and their target molecule, in order to determine the relevance of the structure of the vanillyl ring moiety, as well as to investigate whether a covalent bond may potentially form between the two molecules.

\section{EXPERIMENTAL}

\section{Rationale Behind Chosen Structures}

The input structures that were chosen to compare the contribution of either the hydroxyl or the methoxy substituents to the reactivity of the phenol with acetic acid are shown in Figure 2 along with their appropriate numerical labels. First, a phenol (hydroxybenzene, Figure 2a) was chosen as a reference structure for the others. A hydroxyphenol, $2-\mathrm{OH}$ (1,2-dihydroxybenzene) was generated in two conformations, the first, anti (Figure $2 \mathrm{~b}$ ), with a dihedral angel between $\mathrm{H} 3$ and $\mathrm{C} 1$ of $180^{\circ}$, and the second, syn (Figure 2c), with the corresponding dihedral angle set to $0^{\circ}$. A methoxyphenol, 2-OMe (1-hydroxy-2-methoxybenzene) was constructed in the same manner, similarly labelled anti (Figure 2d) and syn (Figure 2e), in reference to $\mathrm{C} 9$ and $\mathrm{C} 1$ of these structures. In all cases, the $\mathrm{H} 1$ was positioned at a $180^{\circ}$ dihedral angle to $\mathrm{C} 2$, to prevent the formation of an undesired intramolecular hydrogen bond between $\mathrm{H} 1$ and O4. Each of the described structures formed a complex with acetic acid, and then proceeded to react through an addition reaction.

This particular reactant complex was chosen to model the interaction between the phenol variants and glutamic acid or an aspartic acid protein residue. Numerous studies have indicated that glutamic acid is involved in binding of the vanillyl ring of vanilloid structures to the vanilloid receptor, TRPV1, interacting specifically with the hydroxyl functional group. ${ }^{[27-29]}$ Thus, acetic acid may demonstrate a possible methods of interaction between the vanillyl ring and cellular molecules. In addition, the protonated form of acetic acid was used rather than the ionized form, in order to stabilize the molecule and allow it to interact with the phenol derivatives without the use of an explicit water model. Also, this model is meant to demonstrate a reaction that could potentially take place in the binding pocket of a protein, where the environment 
(a)

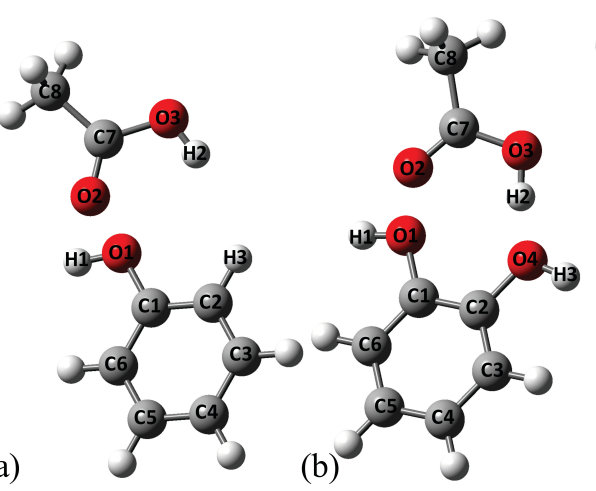

(c)

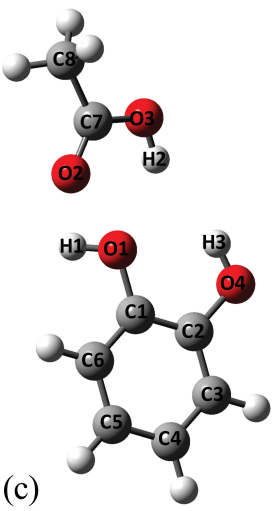

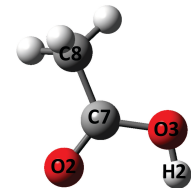

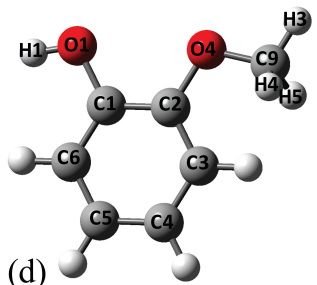

(d)

(e)

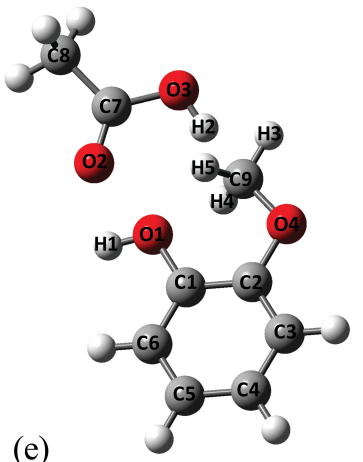

Figure 2. Input structures for reactions between acetic acid and (a) phenol, (b) 2-OH, anti, (c) 2-OH, syn, (d) 2-OMe, anti, and (e) 2-OMe, syn, created with GaussView.

may be slightly different than in the cytosol of a cell. Thus, it is conceivable that in these conditions, glutamic acid may exist in its protonated form.

These structures were used to generate individual reactants, hydrogen-bonded reactant complexes formed with the acetic acid molecule, transition states, and the final products consisting of a covalently bonded complex formed between the phenol variants and acetic acid.

\section{Computational Methods}

The initial structures, including the reactants, transition states, and products, were optimized using the Gaussian 09 (G09) software package. ${ }^{[30]}$ Geometry optimizations were performed using density functional theory (DFT) at the B3LYP level of theory ${ }^{[31]}$ and the 6-31G(d) basis set. In order to most closely mimic the cellular environment in which vanillyl ring structures may be found, calculations were conducted in the aqueous phase, using the SMD solvation model. ${ }^{[32-34]}$ The optimized structures were then used to compute the vibrational frequencies, at the same level of theory and basis set, after which single-point energy calculations were carried out using the G3MP2B3 composite method. ${ }^{[35]}$ From this data, the free energy and the enthalpy of the systems were obtained. In addition, bond lengths were measured between $\mathrm{H} 1$ and $\mathrm{O} 1$ in the reactants and reactant complexes, between $\mathrm{H} 1$ and $\mathrm{O} 2$ as well as $\mathrm{H} 2$ and $\mathrm{O} 1$ in the reactant complexes, $\mathrm{H} 3$ and $\mathrm{O} 3$ in the reactants, reactant complexes, and the products, and between $\mathrm{C} 7$ and $\mathrm{O} 1$ of the products. The GaussView program [36] was used for construction and visualization of all structures.

\section{Comparisons of Free Energy and Enthalpy Changes}

The reaction in which acetic acid (R1) combines with a phenol (R2) to form a reactant complex (RC), followed by a transition state (TS) and finally a covalently bonded product $(P)$, is shown in Figure 3. Any further reactions with this product were not investigated as the high energy barrier of this reaction implies that the comparisons that are made are only hypothetical.

The free energy and enthalpy changes were calculated relative to the energy and the enthalpy of the individual reactants based on the following example:

$$
\Delta G^{\circ}(\mathrm{RC})=G(\mathrm{RC})-G(\mathrm{R} 1)-G(\mathrm{R} 2)
$$

These calculations were carried out for all five phenolic structures, and energy values were recorded in kcal mol-1.

Finally, in order to compare the structures to one another, the relative rates of their reactions were calculated using absolute rate theory, in the form:

$$
\frac{k_{1}}{k_{2}}=e^{-\frac{\Delta G_{1}-\Delta G_{2}}{R T},[37]}
$$

where values of $\Delta G_{1}$ and $\Delta G_{2}$ were the relative free energy values of the transition states.

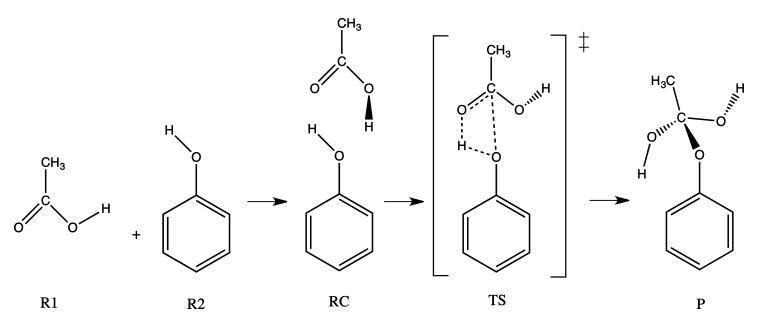

Figure 3. Reaction between phenol and acetic acid; R1 and $\mathrm{R} 2$ represent the reactants, $\mathrm{RC}$ represents the reactant complex, TS denotes the transition state, and $\mathrm{P}$ represents the final product. 


\section{RESULTS AND DISCUSSION}

\section{Free Energy and Enthalpy Changes}

After each structure was optimized and the vibrational frequencies were computed at B3LYP/6-31G(d) level of theory, ${ }^{[31]}$ the enthalpy and free energy values were extracted and used to calculate the changes in enthalpy and free energy of each system, relative to the sum of the individual reactants. These values are summarized in Table 1. In addition, single-point energy calculations were carried out using the G3MP2B3 composite method, ${ }^{[35]}$ and the results of these calculations are also summarized in Table 1. Due to the higher accuracy of this method, the following discussion will focus on the results achieved at this level of theory.

The above calculations suggest that the energy barrier of the reaction may be too high to allow a covalent bond to form between the two molecules. Yet, the variation between the reactivity of the molecules appears to be significant. The syn orientation of the 2-OH structure yields a lower-energy transition state in terms of its free energy change $\left(1.85 \mathrm{kcal} \mathrm{mol}^{-1}\right)$ than the anti orientation. In the same manner, the syn orientation of the 2-OMe structure creates a lower reaction barrier $\left(4.38 \mathrm{kcal} \mathrm{mol}^{-1}\right)$, than its corresponding anti conformation. Furthermore, the free energy change of the product form of the $2-\mathrm{OH}$ structure is only a mere $0.01 \mathrm{kcal} \mathrm{mol}^{-1}$ more stable in the syn orientation than the anti orientation, while the opposite is true in the case of the 2-OMe structures, where the syn orientation is $3.03 \mathrm{kcal} \mathrm{mol}^{-1}$ more stable than the anti. In the case of most transition states and products, the substituted phenols form more stable structures than the nonsubstituted phenol. The exceptions to this pattern occur with the anti orientation of 2-OMe, which has both a higher change in free energy as well as enthalpy in the case of the transition state, and with the syn conformation of the same structure, which forms a less stable product than the nonsubstituted phenol.

Based on the calculated values of $\Delta G^{\circ}$ and $\Delta H^{\circ}$, the structure with the overall lowest activation energy is $2-\mathrm{OH}$ in the syn conformation $\left(49.37 \mathrm{kcal} \mathrm{mol}^{-1}\right.$ and $37.39 \mathrm{kcal} \mathrm{mol}^{-1}$, respectively). In addition, this same structure also yields the most stable product, with both $\Delta G^{\circ}$ and $\Delta H^{\circ}$ values 0.01 to $3.04 \mathrm{kcal} \mathrm{mol}^{-1}$ and 0.65 to $3.51 \mathrm{kcal} \mathrm{mol}^{-1}$, respectively, lower than that of any other structures or conformations. Thus, $2-\mathrm{OH}$ may be the most likely to react with the acetic acid molecule in the syn conformation, while the lower free energy and enthalpy of its product, relative to the other structures, may lower the likelihood of its reverse reaction occurring more readily than the forward reaction. In contrast, the anti orientation of 2-OMe forms a transition state that is considerably less stable than that formed by the other structures $\left(2.00 \mathrm{kcal} \mathrm{mol}^{-1}\right.$ and $2.47 \mathrm{kcal} \mathrm{mol}^{-1}$ less stable than the phenol, in terms of $\Delta \mathrm{G}^{\circ}$ and $\Delta H^{\circ}$, respectively), while the same structure in the syn conformation forms the least stable product on the basis of both its free energy (1.46 to $3.04 \mathrm{kcal} \mathrm{mol}^{-1}$ ) and enthalpy changes (0.96 to $3.51 \mathrm{kcal} \mathrm{mol}^{-1}$ ). Therefore, 2-OMe, anti, may have the least favorable reaction kinetics, while its syn conformation forms the thermodynamically least stable product.

Using the changes in free energy of the transition states, or activation energies of each reaction, the rates of each reaction relative to each other were calculated using the absolute rate theory equation, and the following relationship was observed:

Table 1. Change in free energy and enthalpy of each structure relative to free energy and enthalpy sum values of reactants, calculated at B3LYP/6-31G(d) level of theory as well as the G3MP2B3/6-31G(d) level of theory.

\begin{tabular}{|c|c|c|c|c|c|c|c|c|c|}
\hline & \multirow{2}{*}{ X-phenol } & \multicolumn{4}{|c|}{$\Delta G / \mathrm{kcal} \mathrm{mol}^{-1}$} & \multicolumn{4}{|c|}{$\Delta H / \mathrm{kcal} \mathrm{mol}^{-1}$} \\
\hline & & $\mathrm{R} 1+\mathrm{R} 2$ & $\mathrm{RC}$ & TS & $P$ & $R 1+R 2$ & $\mathrm{RC}$ & TS & $P$ \\
\hline \multirow{5}{*}{$\begin{array}{l}\bar{\partial} \\
\vec{n} \\
m \\
\dot{b} \\
\frac{a}{a} \\
\dot{m} \\
\infty\end{array}$} & $\mathrm{H}$ & 0.00 & 4.98 & 47.76 & 25.32 & 0.00 & -4.71 & 36.06 & 12.13 \\
\hline & 2-OH, anti & 0.00 & 4.01 & 47.13 & 24.25 & 0.00 & -5.76 & 35.20 & 10.72 \\
\hline & 2-OH, syn & 0.00 & 4.65 & 45.01 & 24.14 & 0.00 & -5.31 & 33.03 & 9.98 \\
\hline & 2-OMe, anti & 0.00 & 4.33 & 48.89 & 24.39 & 0.00 & -5.66 & 37.66 & 10.86 \\
\hline & 2-OMe, asyn & 0.00 & 5.25 & 47.26 & 26.78 & 0.00 & -5.05 & 34.03 & 13.09 \\
\hline \multirow{5}{*}{ 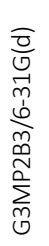 } & $\mathrm{H}$ & 0.00 & 3.24 & 52.57 & 18.75 & 0.00 & -6.45 & 40.87 & 5.56 \\
\hline & 2-OH, anti & 0.00 & 1.64 & 51.22 & 17.18 & 0.00 & -8.13 & 39.29 & 3.66 \\
\hline & $2-\mathrm{OH}$, syn & 0.00 & 2.99 & 49.37 & 17.17 & 0.00 & -6.97 & 37.39 & 3.01 \\
\hline & 2-OMe, anti & 0.00 & 1.81 & 54.57 & 17.18 & 0.00 & -8.18 & 43.34 & 3.64 \\
\hline & 2-OMe, asyn & 0.00 & 3.43 & 50.19 & 20.21 & 0.00 & -6.87 & 36.96 & 6.52 \\
\hline
\end{tabular}




$$
k_{2-\mathrm{OH}, \text { syn }}>k_{2-\mathrm{OMe} \text {, syn }}>k_{2-\mathrm{OH}, \text { anti }}>k_{\text {phenol }}>k_{2-\mathrm{OMe}, \text { anti }}
$$

The $2-\mathrm{OH}$ structure in the syn conformation is therefore more likely to react in this system than either 2OMe structures. The relative reaction rates between $2-\mathrm{OH}$, syn, and 2-OMe, syn, is approximately 4.0 times faster for $2-\mathrm{OH}$. Between the different conformations of the same structures, $2-\mathrm{OH}$, syn, is 22.7 times more reactive than the anti conformation.

\section{DFT Optimized Structures}

After the input structures were optimized, the structures of the transition states for each reaction were examined in order to infer the different stabilizing forces that may be responsible for the differences between reaction kinetics of the different molecules. The transition state structures are shown in Figure 4.

From the above structures, similarities may be noted between the behavior of the hydroxyl- and methoxysubstituted phenols. First, the orientation of either the hydrogen or the methyl group bonded to the oxygen plays a significant role in the stabilization of the transition state. Orientation in the syn conformation in both cases may allow intermolecular hydrogen bonding to occur, stabilizing the structure and lowering the activation energy of the reaction. In this conformation, both $\mathrm{H} 3$ may able to form a hydrogen bond with $\mathrm{O} 3$ (Figures $4 \mathrm{c}$ and $4 \mathrm{e}$ ), although this interaction is presumably stronger in the case of $2-\mathrm{OH}$ due to the larger dipole formed between $\mathrm{H} 3$ and $\mathrm{O} 4$ (Figure 4c) compared to $\mathrm{H3}$ and $\mathrm{C9}$ (Figure 4e). This observation supports the free energies and enthalpy changes that were calculated previously. Orientation of the substituents in the anti position (Figures $4 b$ and $4 d$ ) does not allow for this hydrogen-bonding interaction to occur, and in both conformations causes a less stable transition state structure to form. Moreover, the anti position of 2-OMe (Figure $4 \mathrm{~d}$ ) is further destabilized by the steric strain caused by the methoxy functional group being in the plane of the benzene ring, while the smaller hydroxyl group creates a much less significant strain. In the syn conformation of this structure, however, the methoxy group cannot remain within the plane of the aromatic ring due to the presence of 01 , and is forced to adopt a more favorable position. Yet, in the case of all but the anti conformation of 2-OMe among the substituted phenols, the presence of the substituent creates a more stable structure than is the case with the reference phenol structure (Figure 4a).

Through observation of the products, shown in Figure 5 , the same appears to be true in the case of the $2-\mathrm{OH}$
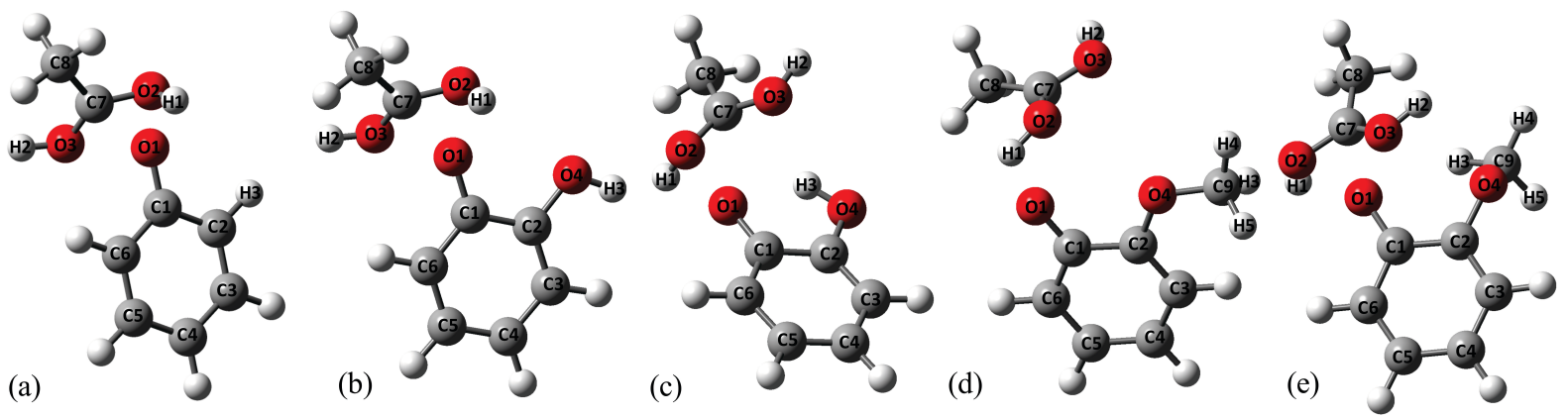

Figure 4. Structure of transition states of reactions between acetic acid and (a) phenol, (b) 2-OH, anti, (c) 2-OH, syn, (d) 2-OMe, anti, and (e) 2-OMe, syn, after optimization at B3LYP/6-31G(d) level of theory.
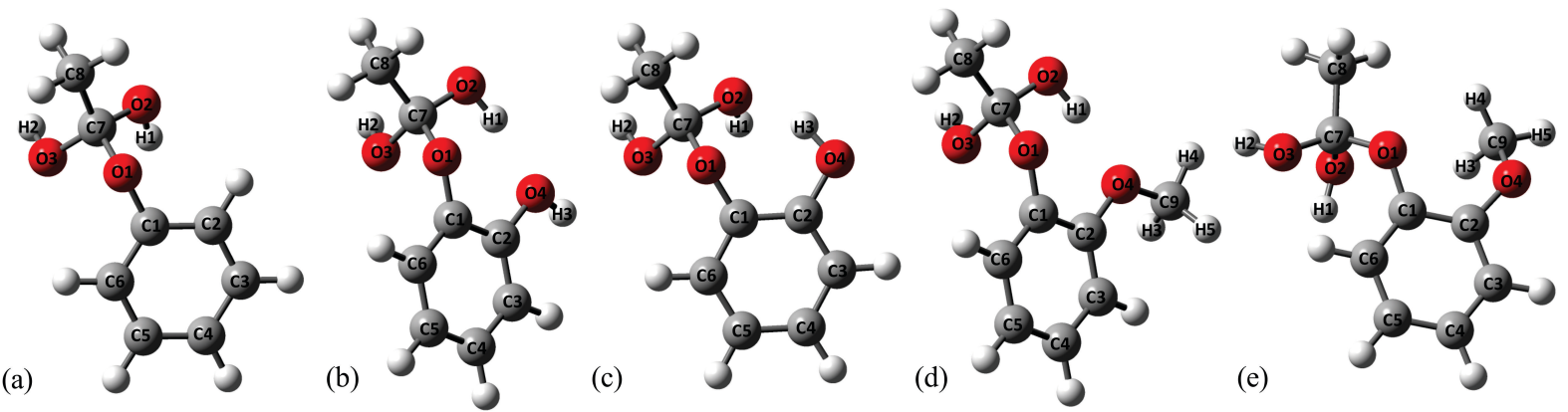

Figure 5. Structure of products of reactions between acetic acid and (a) phenol, (b) 2-OH, anti, (c) 2-OH, syn, (d) 2-OMe, anti, and (e) 2-OMe, syn, after optimization at B3LYP/6-31G(d) level of theory. 
substituents, as with the transition states, since the orientation of the hydroxyl group towards the reacting group appears to stabilize the structure through the formation of an intramolecular hydrogen bond between $\mathrm{H} 3$ and both $\mathrm{O} 1$ and $\mathrm{O} 2$ (Figure 5c). Thus, the syn orientation creates favorable reaction kinetics by decreasing the energy of the transition state relative to the anti orientation, and the resulting product appears to be thermodynamically more stable.

In the case of 2-OMe, syn (Figure 5e), the turning of the methoxy substituent outward of the plane of the benzene is no longer sufficient to prevent steric strain, potentially due to the entire molecule being oriented in such a way to prevent torsional strain within the new addition to its structure. Therefore, this molecule has the highest energy product out of all the structures, and is thermodynamically the least stable. Further, the syn position of 2-OMe (Figure 5d) may allow for a hydrogen bond to form between $\mathrm{H} 1$ and 04 , stabilizing the product relative to the anti position.

\section{Bond Distances}

A hydrogen bond is generally classified as having a length between 1.5-2.5 $\AA^{\left[{ }^{[38]}\right.}$ The measured bond lengths of the optimized structures are summarized in Table 2 . In the RC phase, no significant variation is seen with the hydrogen bond length between $\mathrm{H} 1$ and $\mathrm{O} 1$ based on its different substituents. However, the intermolecular hydrogen bonding shows greater variation, with the strongest bond between $\mathrm{H} 1$ and $\mathrm{O} 2$ being formed by $2-\mathrm{OH}$, syn $(1.780 \AA$ ) , and the weakest being formed by the $2-\mathrm{OH}$ and 2-OMe anti conformations ( $1.855 \AA$ and $1.861 \AA$, respectively). Both substituents strengthen this intermolecular bond relative to the phenol when in their syn orientations, while both anti positioned substituents weaken this hydrogen bond. Conversely, the anti orientation creates a similar stabilizing effect in the case of both substituents for the formation of a hydrogen bond between $\mathrm{H} 2$ and 04 ( $1.883 \AA$ A for $2-\mathrm{OH}$ and $1.880 \AA$ for 2 -OMe). This bond is prevented from forming in the syn position due to steric hindrance.
Another potentially important interaction within the structures is the hydrogen bond that may be formed between $\mathrm{H} 3$ and $\mathrm{O} 1$, which is an intramolecular bond that might affect the reactivity of the molecule. This bond can only be formed in the syn orientation, and is within the range of the length of a hydrogen bond within the $2-\mathrm{OH}$ molecule, although it becomes significantly weaker in the product phase $(2.401 \AA)$ than in the reactant complex ( $2.143 \AA$ ) or the individual dihydroxyphenol (2.161 $\AA$ ). The 2-OMe structure, however, is unable to form this bond at any stage of the reaction (2.612-2.710 ̊).

The final bond that was measured was the newly formed covalent bond between $\mathrm{C} 7$ and $\mathrm{O} 1$ in the products. Although the variation between this bond length is much smaller than the variation between the aforementioned hydrogen bonds, an important point to note is that the shortest bond length is formed in the syn position of $2-\mathrm{OH}$ (1.419 ̊)). As was mentioned in a previous section, this molecule forms the most stable product, despite its forming the least stable transition state. Thus, the bond distance measurements reaffirm the calculations and observations made in the preceding sections of this paper.

\section{CONCLUSIONS}

The characteristics and orientation of different substituents on a phenol molecule were found to affect the molecule's rate of reaction and stability of the products of its addition reaction with acetic acid. Although the high barrier for each reaction may indicate that the reaction is unlikely to occur on its own, the differences in the reaction kinetics and thermodynamic of the different molecules appear to be significant. Calculations of the vibrational frequencies of the optimized structures of the individual reactants, the reactant complex, the transition states, and the products, have shown through both the free energy changes and enthalpy changes that the molecules differ in both reaction kinetics and thermodynamics, despite the high reaction barrier preventing the formation of a covalent bond between phenol

Table 2. Bond distances measured on structures optimized at the B3LYP/6-31G(d) level of theory; single bonds are denoted by '-' whereas hydrogen bonds are denoted by '...', and all bond lengths are measured in $\AA$.

\begin{tabular}{|c|c|c|c|c|c|c|c|c|}
\hline \multirow{2}{*}{ X-phenol } & \multicolumn{2}{|c|}{$\mathrm{H} 1-\mathrm{O} 1$} & \multirow{2}{*}{$\mathrm{H} 1 \cdots \mathrm{O} 2^{(\mathrm{a})}$} & \multirow{2}{*}{$\mathrm{H} 2 \cdots \mathrm{O} 4^{(\mathrm{a})}$} & \multicolumn{3}{|c|}{$\mathrm{H} 3 \cdots \mathrm{O} 1$} & \multirow{2}{*}{$\mathrm{C} 7-\mathrm{O} 1^{(\mathrm{b})}$} \\
\hline & R1 & RC & & & R1 & $\mathrm{RC}$ & $P$ & \\
\hline $\mathrm{H}$ & 0.973 & 0.986 & 1.831 & 2.815 & & & & 1.426 \\
\hline 2-OH, anti & 0.973 & 0.988 & 1.855 & 1.883 & & & & 1.434 \\
\hline 2-OH, syn & 0.973 & 0.989 & 1.780 & 2.714 & 2.161 & 2.143 & 2.401 & 1.419 \\
\hline 2-OMe, anti & 0.973 & 0.988 & 1.861 & 1.880 & & & & 1.433 \\
\hline 2-OMe, asyn & 0.973 & 0.988 & 1.796 & 2.623 & 2.710 & 2.612 & 2.650 & 1.431 \\
\hline
\end{tabular}

(a) Denotes hydrogen bond within reactant complex.

(b) Denotes bond formed within product. 
analogues and acetic acid. The syn position of the 2-OMe substituted phenol was shown to be the most reactive in terms of reaction kinetics, possibly because the orientation of its methoxy group outward of the plane of the benzene ring allowed stabilizing hydrogen bonds to form, in contrast to the case in the similarly-oriented 2-OH-substituted molecule. This molecule was only slightly more stable than the very unstable reference phenol molecule. However, the latter was found to form the thermodynamically most stable product, while 2-OMe, syn, was found to be the least stable.

Although hypothetical, these results may shed light on the potential interactions between either hydroxyl- or methoxy-substituted phenol molecules and carboxylic acid functional groups, which may occur in a number of cellular molecules, namely glutamic acid protein residues. The higher stability of the 2-OH, syn, molecule's product relative to the methoxyphenol structures may be linked to the reasoning behind why such a large number of natural products prefer the methoxy-substituted phenol structure, despite the formation of a dihydroxy benzene structure at an earlier point in the biosynthesis of vanillylring-containing substances. These properties may prevent the formation of stable covalent bonds between natural products containing a vanillyl ring and cellular components.

Further research is required in order to understand more thoroughly the different interactions that may occur between vanillyl rings and intracellular molecules. Functional groups found in different protein residues may react more favorably with the molecules discussed in this work, and may be worth investigating. Also, the antioxidant properties of substances containing vanillyl rings may be attributed to their interaction at these sites with free radicals through numerous mechanisms, although these reactions specifically have yet to be studied in detail through computational chemical measurements.

Acknowledgment. The authors would like to thank the financial support of the "Establishment of collaboration between the higher education and industry (FIEK) involving University of Miskolc for advanced materials and intelligent technologies" Program (GINOP-2.3.4-15-201600004). Béla Fiser thanks the financial support from the National Talent Programme (Project ID: NTP-NFTÖ-161098). We thank the Department of Chemical Informatics (University of Szeged) for allocating some of the computing systems used for this work and László Müller \& Máté Labádi for the administration of these facilities. The Hungarian HPC infrastructure (NIIF Institute) for additional computational resources is also acknowledged.

\section{REFERENCES}

[1] Dictionary of Natural Products, Taylor Fr. Gr., 2017, http://dnp.chemnetbase.com/dictionarysearch/results.do?id=12001328\& props $=\&$ struct $=$ sta rt\&disp=w\&si= (accessed January 24, 2017).

[2] N. J. Walton, M. J. Mayer, A. Narbad, Phytochemistry 2003, 63, 505.

[3] M. B. Hocking, J. Chem. Educ. 1997, 74, 1055.

[4] J. Burri, M. Graf, P. Lambelet, J. Loliger, J. Sci. Food Agric. 1989, 48, 49.

[5] J. P. Kamat, A. Ghosh, T. P. A. Devasagayam, Mol. Cell. Biochem. 2000, 209, 47.

[6] A. Szallasi, P. M. Blumberg, Brain Res. 1990, 524, 106.

[7] S.-H. Choi, B.-S. Suh, E. Kozukue, N. Kozukue, C. E. Levine, M. Friedman, J. Agric. Food Chem. 2006, 54, 9024.

[8] R. Sancho, C. On Lucena, A. Macho, M. A. Calzado, M. Blanco-Molina, A. Minassi, G. Appendino, E. M. Noz, Eur. J. Immunol. 2002, 32, 1753.

[9] D. E. Henderson, A. M. Slickman, S. K. Henderson, J. Agric. Food Chem. 1999, 47, 2563.

[10] T. Ochi, Y. Takaishi, K. Kogure, I. Yamauti, J. Nat. Prod. 2003, 66, 1094.

[11] K. Kogure, S. Goto, M. Nishimura, M. Yasumoto, K. Abe, C. Ohiwa, H. Sassa, T. Kusumi, H. Terada, Biochim. Biophys. Acta 2002, 1573, 84.

[12] J.-D. Kim, J.-M. Kim, J.-O. Pyo, S.-Y. Kim, B.-S. Kim, R. Yu, I.-S. Han, Cancer Lett. 1997, 120, 235.

[13] K. Ito, T. Nakazato, K. Yamato, Y. Miyakawa, T. Yamada, N. Hozumi, K. Segawa, Y. Ikeda, M. Kizaki, Cancer Res. 2004, 64, 1071.

[14] A. Mori, J. O. Kelly, T. Kumagai, J. C. Desmond, M. Pervan, W. H. Mcbride, M. Kizaki, H. P. Koeffler, Cancer Res. 2006, 66, 3222.

[15] N. Olea, Apoptosis 2006, 11, 89.

[16] Y. Iwasaki, A. Morita, T. Iwasawa, K. Kobata, Y. Sekiwa, Y. Morimitsu, K. Kubota, T. Watanabe, Nutr. Neurosci. 2006, 9, 169.

[17] P. Williams, Med. J. Aust. 2006, 185, S17.

[18] S. Chrubasik, M. H. Pittler, B. D. Roufogalis, Phytomedicine 2005, 12, 684.

[19] M. S. Butt, M. T. Sultan, Crit. Rev. Food Sci. Nutr. 2011, 393, 383.

[20] B. H. Ali, G. Blunden, M. O. Tanira, A. Nemmar, Food Chem. Toxicol. 2008, 46, 409.

[21] A. Marsavelski, R. Vianello, Chemistry (Easton) 2017, 23, 2915.

[22] R. M. Borges, S. A. M. Simões, D. Santos, J. A. Martinho, S. Es, J. Phys. Chem. Ref. Data 1998, 27.

[23] C. Funk, P. E. Brodelius, Plant Physiol. 1990, 94, 102. 
[24] C. Funk, P. E. Brodelius, Plant Physiol. 1990, 94, 95.

[25] C. Funk, P. E. Brodelius, Plant Physiol. 1992, 99, 256.

[26] W. Bennet, D. J. Kirby, J. Chem. Soc. 1968, 442.

[27] N. Sukrasno, M. M. Yeoman, Phytochemistry 1993, 32, 839.

[28] F. Yang, X. Xiao, W. Cheng, W. Yang, P. Yu, Z. Song, V. Yarov-Yarovoy, J. Zheng, Nat. Chem. Biol. 2015, 11, 518.

[29] K. Elokely, P. Velisetty, L. Delemotte, E. Palovcak, M. L. Klein, T. Rohacs, V. Carnevale, Proc. Natl. Acad. Sci. U. S. A. 2016, 113, E137.

[30] M. J. Frisch, G. W. Trucks, H. B. Schlegel, G. E. Scuseria, M. A. Robb, J. R. Cheeseman, G. Scalmani, V. Barone, B. Mennucci, G. A. Petersson, H. Nakatsuji, M. Caricato, X. Li, H. P. Hratchian, A. F. Izmaylov, J. Bloino, G. Zheng, J. L. Sonnenberg, M. Hada, M. Ehara, K. Toyota, R. Fukuda, J. Hasegawa, M. Ishida, T. Nakajima, Y. Honda, O. Kitao, H. Nakai, T. Vreven, J. A. Montgomery, J. J. E. Peralta, F. Ogliaro, M. Bearpark, J. J. Heyd, E. Brothers, K. N. Kudin, V. N. Staroverov, R. Kobayashi, J. Normand, K. Raghavachari, A. Rendell, J.
C. Burant, S. S. Iyengar, J. Tomasi, M. Cossi, N. Rega, J. M. Millam, M. Klene, J. E. Knox, J. B. Cross, V. Bakken, C. Adamo, J. Jaramillo, R. Gomperts, R. E. Stratmann, O. Yazyev, A. J. Austin, R. Cammi, C. Pomelli, J. W. Ochterski, R. L. Martin, K. Morokuma, V. G. Zakrzewski, G. A. Voth, P. Salvador, J. J. Dannenberg, S. Dapprich, A. D. Daniels, O. Farkas, J. B. Foresman, J. V. Ortiz, J. Cioslowski, D. J. Fox, Gaussian 09, 2009.

[31] A. D. Becke, J. Chem. Phys. 1993, 98, 5648.

[32] A. V Marenich, C. J. Cramer, D. G. Truhlar, J. Phys. Chem. B. 2009, 113, 6378.

[33] C. C. R. Sutton, G. V Franks, G. Da Silva, J. Phys. Chem. 2012, 116, 11999.

[34] S. Rayne, K. Forest, Theochem. 2010, 949, 60.

[35] R. Janoschek, M. J. Rossi, Int. J. Chem. Kinet. 2002, $34,550$.

[36] R. D. Dennington, T. A. Keith, J. M. Millam, GaussView, 2009.

[37] H. Eyring, J. Chem. Phys. 1935, 3, 107.

[38] G. A. Jeffrey, An Introduction to Hydrogen Bonding, Oxford University Press, New York, 1997. 